\title{
Self-Efficacy in Students with and Without Physical Impairment
}

\author{
Narsimulu $^{1 *}$
}

\section{ABSTRACT}

There has been long term and systematic denial of opportunities to people with disabilities, particularly in fields such as education, employment, housing, transport, cultural life and access to public places and services. The mistreatment and oppression inflicted on individuals who have some form of disability or impairment has been well documented.

The present study analyzed associations of general self-efficacy beliefs with psychological adjustment, academic achievement, and attainment of developmental tasks in various hostels and homes with physical impairment and same group peers without physical impairment. In this study the main objective is to compare the self efficacy of physically impaired and without impaired. Between-group differences in levels of self-efficacy beliefs were small. On average, higher self-efficacy beliefs predicted positive change in psychological adjustment (lifesatisfaction and emotional symptoms) and academic achievement as well as greater progress in the attainment of developmental tasks of adolescence. However, for emotional symptoms and the discrepancy between desired and present attainment of developmental tasks we found such an effect only for students without physical impairment.

This paper also presented by me in National Conference on "Challenges of Contemporary Life Role of Positive Psychology \& 9th Annual Conference of Indian Association of Mental Health from 22nd to 24th January 2015 and not publish myself the same in any journal.

We conclude that students with physical impairment may benefit from measures that both promote supportive external conditions for goal attainment and increase the self-management skills needed to translate self-efficacy beliefs into accomplishment of goals and related positive feelings.

Keywords: Self-Efficacy, Physical, without Physical, Impairment.

According to Bandura (1977, 1997), an individual may gain a greater sense of self-efficacy from four informational sources, they are: 1) performance accomplishments, 2) vicarious learning, 3) social persuasion, and 4) emotional arousal. Performance accomplishment is based on an individual's past success in performing a task or behavior. If an individual has already performed

\footnotetext{
${ }^{1}$ M.A(Psy.), M.Ed, M.Phil(Psy), (Ph.D(Psy), Research Scholar, Dept. of Psychology, Osmania University, Hyderabad

*Responding Author

(C) 2016 I Narsimulu; licensee IJIP. This is an Open Access Research distributed under the terms of the Creative Commons Attribution License (http://creativecommons.org/licenses/by/2.0), which permits unrestricted use, distribution, and reproduction in any Medium, provided the original work is properly cited.
} 


\section{Self-Efficacy in Students with and Without Physical Impairment}

a certain behavior well, then he or she is likely to have stronger self-efficacy beliefs with regards to that behavior. Bandura (1997) posited that performance accomplishment, or enactive mastery, is the most influential source for self-efficacy beliefs. A second source of self-efficacy is vicarious learning. Vicarious learning takes place when an individual observes and learns from the behaviors of others. If an individual observes someone else doing well at a particular task of interest, he or she is more likely to engage in that same task. Vicarious learning is usually more effective if the other individual modeling the behavior is similar to the observer and if the other individual is rewarded for his or her efforts. Social persuasion is the third primary informational source for self-efficacy beliefs. If others give an individual reinforcement for a behavior, then he or she is likely to have higher self-efficacy for that behavior.

Therefore, encouragement is a powerful tool for increasing self-efficacy beliefs in others. A final source influencing self-efficacy beliefs is physiological and affective states. Bandura (1997) indicated that emotional/somatic information is especially significant for behaviors involving health functioning, coping with stressors, and physical accomplishments. Individuals utilize both their moods and their bodily sensations when formulating their self-efficacy beliefs for certain behaviors. If an individual engages in a particular behavior and experiences distressing sensations, for example anxiety, he or she is usually less likely to participate in that behavior again. These four sources of self-efficacy beliefs directly impact several behavioral outcomes.

The three primary behavioral outcomes influenced by self-efficacy beliefs are: 1) approach versus avoidance, 2) performance, and 3) persistence (Bandura, 1977, 1997). An individual with high self-efficacy for a particular behavior is more likely to approach, better perform, and persist at that behavior. On the other hand, an individual with low self-efficacy for a specific behavior is less likely to approach, perform well and/or persist at that behavior.

Researchers have explored the utility of Bandura's $(1977,1997)$ theory of self efficacy in a wide range of settings for understanding behavior for over 20 years. Self efficacy is essentially an individual's belief in his or her ability to perform a specific task or behavior. Bandura (1997) emphasized that self-efficacy is not a general quality possessed by individuals, but rather specific beliefs an individual may have around particular tasks or behaviors. For example, an individual with higher social self-efficacy is said to have greater confidence in his or her ability to interact with others socially. Self-efficacy beliefs come from several different informational sources and influence certain behavioral outcomes.

\section{Perceived Self-efficacy}

The term "perceived self-efficacy" refers to people's beliefs about their capability to influence events that affect their lives and to accomplish personal goals. Self-efficacy beliefs determine how people feel, think, motivate themselves and behave. Such beliefs produce diverse effects through four major processes: cognitive, motivational, affective, and selection processes (Bandura, 1982, 1997). Bandura argues that repeated experiences with success in challenging 


\section{Self-Efficacy in Students with and Without Physical Impairment}

tasks are prerequisites to a strong sense of self-efficacy. His theoretical framework reflects that in order to be successful one requires some sense of self-efficacy, a perception of oneself as being able to perform effectively. For example, self-efficacy beliefs affect the selection of goals, the investment of efforts, and the persistence with these efforts (Bandura, 1997). Thus, low selfefficacy beliefs may lead to low aspirations and lack of persistence, as well as low levels of academic achievement and goal attainment in general.

It has been suggested that self-efficacy is a primary factor in adjustment to physical impairment. Acquiring realistic expectations about one's competencies is one of the most important aspects of adjustment to physical impairment. Because origins of self-efficacy lie in the appraisal of past performances (Bandura, 1982, 1997), past self-efficacy beliefs may no longer be realistic when visual abilities decline. The development of realistic expectations about one's competencies is also necessary in the case of congenital physical impairment because young people have to learn whether they could attain the goals that are typical for their age group The analysis of predictors and effects of self-efficacy beliefs of young people with physical impairment is important for general education and rehabilitation because the development of positive self-efficacy beliefs could be one way of promoting skilled behavior and success in the academic context and other fields of life.

Whereas some studies have assessed self-efficacy beliefs in older adults with physical impairment (Brown \& Barrett, 2011; Ormel, Kempen, Penninx, Brilman, Beekman, \& VanSonderen, 1997; Talbert-Kipasa, 2008), there is a surprising lack of research on this topic in children and adolescents with physical impairment. Thus, the goal of the present study was to analyze self-efficacy beliefs in adolescents with physical impairment.

In the first research question, we ask whether levels of self-efficacy differ between adolescents with and without physical impairment. In the second research question, we analyze whether higher levels of self-efficacy would be associated with better psychological adjustment, academic achievement, and attainment of developmental tasks. We also ask whether adolescents with and without physical impairment benefit to a similar extent from high self-efficacy beliefs with regard to these outcome variables. Age is used as the control variable in these analyses because the average attainment of developmental tasks increases with age. We focus on general self-efficacy beliefs rather than on domain-specific beliefs (e.g., regarding academic success) because the former are expected to be associated with a broader range of outcome variables, although the size of the associations may be lower than between domain-specific beliefs and the related domain-specific outcomes (Bandura, 1997).

\section{Self-efficacy in Individuals with and without Physical Impairment}

The origins of self-efficacy lie in appraisals of past performances (Bandura, 1982, 1997). Several factors may contribute to reduced self-efficacy beliefs of students with physical impairment. First, because visual impairment is, on average, associated with reduced social (Gronmo \& 


\section{Self-Efficacy in Students with and Without Physical Impairment}

Augestad, 2000; Huurre \& Aro, 1998) and physical competence (Gronmo \& Augestad, 2000) as well as restrictions in daily living (Talbert-Kipasa, 2008), young people with physical impairment may exhibit lower levels of self-efficacy beliefs than their peers without visual impairment. Second, public misconceptions about blindness as well as low expectations and over-assisting behavior of significant others may limit the development of skills that would be needed to succeed and to compete with sighted peers (Adenzato, Ardito, \& Izard, 2006).

However, Blake and Rust (2002) found that general self-efficacy scores of young people with disabilities were similar to scores from the normative sample. Similarly, in another study no significant differences between adults with and without visual impairment were found (Suzukamo, Hirokai, \& Trumotu, 2001). Nonetheless, Brown and Barrett (2011) found that higher levels of visual impairment were associated with lower self-efficacy of older adults. As our search in electronic data bases (Medline, PsycLit, Google Scholar) did not identify comparative studies of self-efficacy of adolescents with and without physical impairment, the first goal of our study was to test whether the levels of self-efficacy beliefs would differ between both groups. Because Schieman and Campbell (2001) observed that differences in levels of selfefficacy between adults with and without disability increased with age, we also wanted to explore whether differences between the levels of self-efficacy beliefs of students with and without physical impairment would vary by age and change over a one-year period.

\section{Associations of Self-efficacy with Psychological Health and Successful Development}

It has been suggested that higher self-efficacy beliefs predict success in life and mental health. In adults with visual impairment, self-efficacy beliefs were associated with lower levels of anxiety and depression (Brown \& Barrett, 2011; Dodds, Ferguson, Ng, Flannigan, Hawes, \& Yates, 1994; Horowitz, Reinhardt, \& Kennedy, 2005) as well as higher levels of vision-specific mental health (Talbert-Kipasa, 2008) and general life-satisfaction (Brown \& Barrett, 2011). To our knowledge, no such data are available for adolescents with physical impairment.

Relevant indicators of adolescents' success in life may be academic achievement and the attainment of age-associated developmental tasks. Research not specific to physical impairment indicates that self-efficacy is a strong and proximal predictor of academic achievement. This is found in studies with students without physical impairment for general self-efficacy beliefs as well as for academic self-efficacy beliefs (Weiser \& Riggio, 2010). These positive associations may reflect children's and adolescents' "insight" into abilities that affected their previous performance and the self-fulfilling or motivational effects of self-beliefs (Chamorro-Premuzic, Harlaar, Greven, \& Plomin, 2010).

According to Havighurst (1948), developmental tasks are biologically, socially, and individually determined tasks that must be completed in a particular period of life, such as childhood and adolescence. Developmental tasks of adolescence include, among others, gaining autonomy from parents, building peer relations, and starting to prepare for a future profession. Again, 


\section{Self-Efficacy in Students with and Without Physical Impairment}

associations of self-efficacy beliefs with success in mastering age-associated developmental tasks have not been assessed in young people with physical impairment. In students without physical impairment, Schönpflug and Jansen (1995) found that adolescents with stronger "selfas-agent beliefs" preferred active strategies in coping with developmental tasks and showed smaller discrepancies between present and desired attainments in three developmental tasks (gaining autonomy from parents, developing professional expertise, developing opposite-sex friendships). However, in that study self-as-agent beliefs were a mixture of self-esteem, locus of control, and self-efficacy beliefs. Thus, it remained open whether self-efficacy beliefs in particular or general positive self-evaluations were related to success with developmental tasks. A small number of other studies have focused on a single developmental task and have found self-efficacy to predict success with attaining it (e.g., with regard to preparation for a career; Pinquart, Juang, \& Silbereisen, 2003).

Due to the lack of studies that compare young people with and without physical impairment, it has not been tested whether both groups benefit from self-efficacy beliefs to the same extent. Because studies of individuals with visual impairment (Brown \& Barrett, 2011; Dodds et al., 1994; Horowitz et al. 2005) and studies of individuals without impairment (Schönpflug \& Jansen, 1995; Weiser \& Riggio, 2010) have observed associations of self-efficacy beliefs with desirable psychosocial outcomes, we expected to find positive associations of self-efficacy beliefs with indicators of psychological adjustment, academic achievement, and success with attaining developmental tasks in both groups. Nonetheless, we expected that the effect sizes may vary between these groups. On the one hand, self-efficacy beliefs become more important if goals are not easily attainable and success is not self-evident (Locke, Frederick, Lee, \& Bobko, 1984). As some goals are more difficult to attain for students with physical impairment than for peers without this kind of impairment (such as gaining access to a peer group; Pfeiffer \& Pinquart, 2011), adolescents with physical impairment might benefit more from self-efficacy beliefs. On the other hand, self-efficacy beliefs may only promote success in life and psychological adjustment as long as goals are attainable. For example, a belief in one's ability to drive a car will not help in obtaining a driving license if the law does not allow persons with a particular degree of visual impairment to apply for such a license. Thus, individuals with physical impairment may in some cases benefit less from high self-efficacy beliefs. Because of the contradictory theoretical arguments, we did not state a specific hypothesis with regard to differences in the size of association of self-efficacy with psychosocial outcomes in individuals with and without physical impairment.

\section{METHOD}

To Study the Self-Efficacy in Students With and Without Physical Impairment

\section{Objectives of the study:}

1. To study and compare the General self-efficacy beliefs in students with and without physical impairment. 


\section{Self-Efficacy in Students with and Without Physical Impairment}

2. To Compare the Self Efficacy and life satisfaction of their impairment and without impairment.

\section{Hypotheses of the study:}

1. The general self-efficacy would be differ from their impairment and without impairment

2. Self efficacy and life satisfactions would be depend on their physical impairment.

\section{Participants}

We used data from the first and second time of measurement from Adolescents with physical impairment were recruited from various orthopedically handicapped students homes and hostels. for students with physical impairment. Because most these homes and hostels adolescents with physical impairment attend various colleges. After I had gained the permission from the wardens and disability section authorities. At the time of measurement $\left(\mathrm{T}_{1}\right), 40$ students with physical impairment and 40 students without physical impairment participated.

\section{Sample}

- $\quad$ Physically challenged $=40$ Students (Various Orthopedically Challenged hostels)

- $\quad$ Without Challenged = 40 Students (Various Normal Schools and Colleges)

- Age Group: $15-20$ years

\section{Measures}

\section{Self-efficacy}

I used the General Self-Efficacy Scale (Schwarzer \& Jerusalem, 1995) which consists of 10 Likert-type items. A sample item is, "I can always manage to solve difficult problems if I try hard enough" ( 1 = not at all true, 2 = hardly true, 3 = moderately true, 4 = exactly true). This scale is available in 30 languages and has been used in a large number of studies around the globe (Schwarzer, R., 2006).

\section{Psychological adjustment}

Two indicators of psychological adjustment were used, one focusing on positive feelings (life-satisfaction; Diener, Emmons, Larsen, \& Griffin, 1985) and one focusing on negative feelings (emotional symptoms; Goodman, 1997). Life-satisfaction was assessed with the 5 items of the Satisfaction with Life Scale (Diener et al., 1985), which is one of the most widely used life-satisfaction scales. A sample item is, "I am satisfied with my life" (1 = strongly disagree, 7 = strongly agree)

\section{Analysis}

Means and standard deviations of the study variables are presented in Table 1. Adolescents with physical impairment had lower levels of life-satisfaction, However, the two groups did not differ in the size of discrepancies between desired and present attainment of the developmental tasks. 
Table 1. Means and standard deviations of the study variables

\begin{tabular}{|l|l|l|l|l|l|}
\hline & \multicolumn{2}{l}{ Physical impairment } & No physical impairment & \\
\hline Variable & $M$ & $S D$ & $M$ & $S D$ & $F$ \\
\hline Self-efficacy & 28.23 & 5.80 & 29.12 & 4.88 & 2.73 \\
\hline Life-satisfaction & 21.86 & 7.36 & 23.31 & 6.16 & 4.54 \\
\hline
\end{tabular}

Table 2. Associations of physical impairment status and self-efficacy with changes in lifesatisfaction

\begin{tabular}{|l|l|l|l|}
\hline & Self Efficacy & Life Satisfaction & t \\
\hline Physical Impairment & 1.29 & .09 & 2.19 \\
\hline Without Impairment & .15 & .18 & 3.66 \\
\hline
\end{tabular}

As indicated in Table 2, all dependent variables showed considerable correlational stability over time. Higher age predicted faster progress with attaining adolescent developmental tasks but did not predict change among the other outcome variables. The amount of change of three of the five assessed variables varied between individuals with and without visual impairment. Students who had no visual impairment showed more improvement in life-satisfaction

\section{DISCUSSION}

The present study found similar levels of self-efficacy beliefs among students with and without physical impairment, although these beliefs showed more positive change with visual impairment. Higher self-efficacy beliefs were, on average, associated with more positive change of the outcome variables. However, only students without physica impairment benefited from high self-efficacy beliefs with regard to levels of life-satisfaction, we start the discussion with differences in study variables between students with and without physical impairment, followed by the main effects and interaction effects of self-efficacy beliefs.

The observed lower levels of psychological adjustment among young people with visual impairment as compared to their peers without visual impairment are consistent with results of previous studies (Huurre \& Aro, 2000). This between-group difference may be based on difficulties in participating in activities charged with vision content, higher dependency on others, negative ideas about physical attraction, and being discriminated against by others (Huurre \& Aro, 2000; Lifshitz, Hen, \& Weisse, 2007). Nonetheless, average between-group differences were small.

Between-group differences in the level of self-efficacy beliefs were small, and the interaction effect of physical impairment status and time of measurement indicates that students with physical impairment caught up with the marginally significant backlog that was observed at measurement Our results are consistent with the study by Suzukamo et al. (2001) on self- 


\section{Self-Efficacy in Students with and Without Physical Impairment}

efficacy of older adults with visual impairment. As we assessed general self-efficacy beliefs, individuals with and without visual impairment have opportunities to experience the success of their efforts (Bandura, 1982) although the specific opportunities might differ between the two groups. Between-group differences in domain-specific self-efficacy beliefs have to be tested in future studies. Interestingly, i found an age-associated increase in self-efficacy beliefs in students without but not with physical impairment. A significant small positive association of age with general self-efficacy beliefs has also been observed in a data set of more than 6,800 adolescents without visual impairment (Schwarzer, 2006). These results indicate that opportunities for experiencing success and other sources of general self-efficacy beliefs tend to increase across adolescence in young people without visual impairment. However, sources of self-efficacy among students with physical impairment, such as the development of compensatory skills, are not dependent upon age.

\section{FINDINGS \& CONCLUSION}

At present measure of self-efficacy beliefs in contrast to some previous studies that used an invalidated mix of self-efficacy items some limitations specific to the present study should be mentioned. First, we had to rely on adolescent self-reports. As students with physical impairment from lower school tracks may be more likely to have other disabilities also, it remains open whether similar results would be found in students with additional learning disabilities or other disabilities. Third, as we recruited students with visual impairments from special schools for this group, we focused on young people with severe physical impairments. Students who can attend regular schools because of lower levels of physical impairment might benefit more from high self-efficacy beliefs.

There are three main conclusions can be drawn from the present study. First, whereas researchers in the field of physical impairment very often seek for elevated levels of psychological and social problems, our results indicate that young people with physical impairment may be even more successful than their peers with regard to some criteria (e.g., making career choices), at least in students from the highest school track. Second, although students with physical impairment may benefit less from high self-efficacy than students without physical impairment with regard to some outcome variables, our results indicate that self-efficacy beliefs are a relevant inner resource for students with physical impairment.

Thus, ensuring high self-efficacy is important for all students (independent of physical status). Third, regarding future research needs we recommend studies on self-efficacy beliefs of students with visual impairment from lower school tracks and from integrated schools. In addition, future research should also include domain-specific self-efficacy scales in order to test in which domains young people with visual impairment may or may not show lower levels of self-efficacy as compared to their peers. Finally, future studies should explore external factors affecting the student with physical impairment (e.g., discrimination, attitudes of the society at large, 


\section{Self-Efficacy in Students with and Without Physical Impairment}

misconceptions about physical impairment by parents and teachers) that may contribute to the smaller impact of higher self-efficacy on the reduction of negative emotions.

\section{IMPLICATIONS}

Young people with physical impairment have similar levels of self-efficacy to those of their peers without Physical impairment although they benefit less from them. Thus, there is interventions may be needed for increasing self-efficacy beliefs among adolescents with physical impairment. Interventions should instead focus on increasing the beneficial effect of self-efficacy beliefs, for example by training self-management skills that would be needed to cope with stressors and worries; or by promoting external conditions that support positive effects of efficacy, such as increasing the probability of success.

\section{REFERENCES}

Adenzato, M., Ardito, R. B., \& Izard, E. (2006). Impact of maternal directiveness and over protectiveness on the personality development of a sample of individuals with acquired blindness. Social Behavior \& Personality, 34(1), 17-26.

Aiken, L. S. \& West, S. G. (1991). Multiple regression: Testing and interpreting interactions. Newbury Park, CA: Sage.

Bandura A. (1982). Self-efficacy mechanism in human agency. American Psychologist, 37(2), $122-147$.

Bandura, A. (1997). Self-efficacy: The exercise of control. New York: Freeman.

Blake, T. R., \& Rust, J. O. (2002). Self-esteem and self-efficacy of college students with disabilities. College Student Journal, 36(2), 214-221.

Brody, B. L., Williams, R. A., Thomas, R. G., Kaplan, R. M., Chu, R. M., \& Brown, S. I. (1999). Age-related macular degeneration: A randomized clinical trial of a self-management intervention. Annals of Behavioral Medicine, 21(4), 322-329.

Brown, R. L., \& Barrett, A. E. (2011). Visual impairment and quality of life among older adults: An examination of explanations for the relationship. Journals of Gerontology -- Series B: Psychological Sciences and Social Sciences, 66B(3), 364-373.

Carlstrom, K. H., Kaff, M. S., \& Low, A. R. (2009). Diversity and career advising. In K. F. Hughey, D. B. Nelson, J. K. Damminger, \& B. McCalla-Wriggins (Eds.), Handbook of career advising (pp. 113-145). San Francisco: Jossey-Bass.

Chamorro-Premuzic, T., Harlaar, N., Greven, C. U., \& Plomin, R. (2010). More than just IQ: A longitudinal examination of self-perceived abilities as predictors of academic performance in a large sample of UK twins. Intelligence, 38(4), 385-392.

Cho, H. J., \& Palmer, S. B. (2008). Fostering self-determination in infants and toddlers with visual impairments or blindness. Young Exceptional Children, 11(4), 26-34.

How to cite this article: Narsimulu (2016), Self-Efficacy in Students with and Without Physical Impairment, International Journal of Indian Psychology, Volume 3, Issue 3, No. 6, DIP: 18.01.102/20160303 